\title{
O ensino das partículas modais alemãs: estratégias didáticas em ALE
}

\section{The Teaching of German Modal Particles: Didactic Strategies in GFL}

\author{
Marceli Cherchiglia Aquino* \\ *Universidade de São Paulo (USP), São Paulo, São Paulo / Brasil \\ marceli.c.aquino@gmail.com
}

http:/ / orcid.org/0000-0003-0518-7639

\begin{abstract}
RESUMO: A investigação das partículas modais alemãs (doravante PMs) vem ganhando cada vez mais atenção no ensino de alemão como língua estrangeira (ALE). As dificuldades de aquisição das PMs podem ser superadas com a aplicação de estratégias didáticas, como: a análise contextual, a qual são diretamente dependentes; o conhecimento da função nuclear de cada PM; a distinção de seus homônimos; intenções e expectativas dos interlocutores; a análise contrastiva dos equivalentes funcionais em português. Assim, as PMs devem ser analisadas considerando seus aspectos gramaticais e pragmáticos. Oferecemos neste trabalho soluções didáticas e sugestões de materiais (filmes e quadrinhos) para a mediação das PMs em ALE para brasileiros, incentivando o desenvolvimento de habilidades comunicativas.
\end{abstract}

PALAVRAS-CHAVE: partículas modais alemãs; ensino de língua alemã; estratégias didáticas

\begin{abstract}
German modal particles (henceforth MPs) have been receiving increasingly attention, particularly in the context of teaching German as a foreign language (GFL). Difficulties concerning the proper acquisition of MPs can be overcome by didactic strategies such as: contextual analysis, from which MPs are directly dependent of; the nuclear function of each MP; the distinction between them and their homonyms; the intentions and expectations of the interlocutors; and contrastive analysis of its functional equivalents in Portuguese. Therefore, MPs can only be effectively analyzed if their grammatical and pragmatic aspects are considered. In this work, strategies and didactic materials (movies and comics) that may help teachers present MPs in GFL classes for Brazilians are suggested, focusing on the acquisition of communicative skills in German language.
\end{abstract}

KEYWORDS: German modal particles; teaching German as a foreign language; didactic strategies 


\section{Introdução}

De forma geral, as partículas modais (doravante PMs) em língua alemã $^{1}$ são classificadas como palavras que não sofrem flexão, englobandose nessa classificação elementos que são normalmente caracterizados como advérbios, conjunções e preposições (WEYDT 1983, p. 13). Além de não flexionáveis, as PMs apresentam outras características delimitadoras, como: não são acentuadas; não podem ser negadas ou intensificadas; não respondem perguntas (sim e não); podem ser combinadas com outras PMs; não formam um enunciado sozinhas; apresentam função nuclear específica; estão sintaticamente e gramaticalmente integradas na sentença; são posicionadas no campo central (Mittelfeld); ocorrem em tipos específicos de sentenças; têm escopo sobre toda a sentença; são usadas especialmente em fala coloquial, mas não exclusivamente; apresentam homônimos não modais em outras categorias; têm sentido inferencial (WEYDT, 1969; KRIVONOSOV, 1989; ABRAHAM, 1991b; HELBIG; KÖTZ, 1991).

Ainda, estes elementos modais atribuem o máximo de informação com menor esforço cognitivo, especificam a relação entre falante e ouvinte (AQUINO, 2016, p. 74), se referem a um acontecimento anterior à proposição que pode ser recuperado contextualmente (DIEWALD, 2006, p. 406) e indicam significados emocionais e afetivos (DEGAND; CORNILLIE; PIETRANDREA, 2013, p. 14-15). Diewald (2013, p. 22), afirma ainda que as PMs são modos convenientes e sutis de introduzir implicações, suposições e alusão de maneira implícita, e que este potencial é a razão da riqueza das funções comunicativas e retóricas destes elementos.

Logo, os usos modais podem ser considerados como ajustadores contextuais, tendo a função de checar/certificar se os interlocutores estão entendendo uns aos outros (VASKÓ; FRETHEIM, 1997, p. 235), destacando aquilo que merece atenção. Segundo a Teoria da Mente (ToM) (ABRAHAM, 2010) essa habilidade linguística de identificar as informações conhecidas entre os interlocutores e acessar o ambiente cognitivo é chamada de deslocamento duplo (ABRAHAM; LEISS, 2012, p. 11). De acordo com os postulados dessa teoria, por meio das PMs os indivíduos envolvidos no processo interpretativo são divididos em múltiplas personalidades e pontos

\footnotetext{
${ }^{1}$ As 15 PMs mais comuns em alemão: aber, auch, bloß, denn, doch, eben, eigentlich, etwa, halt, ja, mal, nur, schon, vielleicht, wohl(HELBIG; BUSCHA, 2002, p. 421; DUDEN, 2016, p. 602).
} 
de vista para que a comunicação seja bem-sucedida. $O$ falante abre espaço para que o ouvinte avalie o sucesso da proporção realizada, negociando o significado.

Nos últimos anos, tem-se observado uma crescente preocupação em investigar questões voltadas à aquisição de competências pragmáticas e sociolinguísticas no ensino de alemão como língua estrangeira (ALE). Estas competências são de grande relevância para o desenvolvimento de habilidades comunicativas e interculturais, cruciais para o sucesso da aquisição de uma língua estrangeira (doravante LE). Neste sentido, a mediação das PMs desempenha um papel importante no ensino de ALE, pois possibilita o uso culturalmente apropriado dos meios linguísticos (HELBIG, 1990; BUSSE, 1992; HEGGELUND, 2001; WEYDT 2003; THURMAIR 2010; AQUINO, 2012).

De acordo com Helbig (1990, p. 12), as PMs representam um fenômeno típico da língua alemã e são imprescindíveis para o relacionamento social e, portanto, devem ser levadas em consideração em uma abordagem comunicativa em ALE. Não obstante, mesmo sendo frequentes na comunicação diária, as PMs apresentam um aspecto complexo e assim, um desafio para a aquisição de ALE, não sendo muitas vezes abordadas em sala de aula (HELBIG; KÖTZ, 1991, p. 7). Contudo, Duch-Adamczyk (2012, p. 27) pontua que as PMs também apresentam dificuldade para falantes nativos, já que são assimiladas inconscientemente.

Para a Teoria da Relevância (doravante TR) (SPERBER; WILSON, 2005), por razão da forma como nossos sistemas cognitivos se desenvolveram, os seres humanos possuem uma tendência automática para maximizar a relevância. A maximização da relevância é, por sua vez, definida em termos de esforço e efeitos cognitivos envolvidos para chegar a uma interpretação satisfatória do estímulo recebido. O esforço de processamento consiste no dispêndio de energia pelo sistema cognitivo para alcançar a interpretação de tal estímulo. Os efeitos cognitivos representam o resultado da interação produtiva, isto é, relevante, entre o estímulo e o conjunto de suposições armazenadas no sistema cognitivo (AQUINO, 2017a, p. 68).

Segundo esta premissa, para alcançar a relação adequada entre esforço e efeito e acessar a intenção pretendida na comunicação, é preciso identificar as informações do ambiente cognitivo mútuo, isto é, as informações que o comunicador acredita compartilhar com seu ouvinte. Neste sentido, as PMs funcionariam como pistas comunicativas que direcionariam a geração 
de implicaturas para o processamento inferencial. Consequentemente, elas podem ser descritas como marcadores gramaticais contextuais, com a função principal de relacionar o enunciado com um conhecimento particular anterior ao momento da comunicação, considerando as intenções e expectativas dos participantes da interação e, como estas são acessadas na busca de sentido. Assim, cabe aos interlocutores negociar as informações contextuais atreladas a inferências proporcionadas pelas PMs.

As PMs implicam, portanto, a avaliação sobre o grau de relevância de cada informação, isto é, o conteúdo provável de provocar maior acréscimo de conhecimento com o menor custo de processamento. Sendo elementos que fazem parte do ambiente cognitivo de nativos, elas são imediatamente reconhecidas e processadas. Por outro lado, o processamento das PMs pode ser mais custoso para o falante não nativo, pois essas informações contextuais não estão totalmente acessíveis em seus ambientes cognitivos (AQUINO, 2017a, p. 66).

O desafio do uso e compreensão das PMs advém, assim, de diversos determinantes, como a sua dependência contextual, o significado atrelado a inferências, a negociação do ambiente cognitivo dos interlocutores, além da existência de homônimos (como advérbios, conjunções e marcadores do discurso) em outras classes de palavras (esta questão será discutida na seção 3) e a falta de equivalentes diretos na maioria dos idiomas. Não obstante, estas dificuldades podem ser superadas por meio do desenvolvimento de estratégias didáticas que abordem estas questões de maneiras simples e direta, levando em consideração os aspectos gramaticais, pragmáticos e socioculturais.

Propomos neste artigo algumas sugestões para superar tais dificuldades, isto é, abordar os aspectos gramaticais, as funções nucleares de cada PM, e encontrar equivalentes funcionais em português. As atividades propostas são pautadas em materiais com linguagem autêntica (filmes e quadrinhos), como forma de abordar a temática das PMs em diversos níveis de conhecimento de ALE. Defendemos, portanto, que é possível oferecer regras claras para o ensino de aprendizagem de PMs por meio de tarefas dinâmicas, material autêntico do gênero escrito e falado. Evidenciamos ainda que é importante incentivar uma postura autônoma e reflexiva por parte dos alunos, auxiliando assim a compreensão das funções, usos e significados das PMs. 
Nas próximas seções abordaremos o papel das PMs em aulas de ALE, esboçando alguns trabalhos fundamentais na área. Na terceira seção discutiremos sobre as estratégias de ensino e aprendizagem para a mediação destes elementos modais. E finalmente, apresentamos sugestões com filmes e quadrinhos, que podem ser utilizados no sentido de colocar em prática as estratégias didáticas sugeridas neste trabalho.

\section{O papel das PMs em ALE}

Um objetivo importante na metodologia de ensino de LE é a capacidade de utilizar o idioma em diversas situações do dia-a-dia. Neste sentido, as PMs apresentam aspectos comunicativos indispensáveis em língua alemã, funcionando como ferramentas para negociar inferências entre os interlocutores (AQUINO, 2017b, p. 157). Fora de um contexto de imersão, é particularmente importante fazer o melhor uso possível do ambiente em sala de aula para mediação destes elementos.

Diversos autores compactuam com a visão de Weydt (2003, p. 16), que a linguagem rica em PMs é mais agradável, humana e flexível. Helbig e Kötz (1991, p. 7) argumentam que, mesmo sem o conhecimento acerca das PMs, os aprendizes de ALE podem se comunicar com sucesso na língua alemã, no entanto, eles seriam incapazes de entender ou expressar certas nuances. Para Busse (1992, p. 37), o uso da língua sem PMs é marcado como atípica, fazendo com que falte ao aluno o desenvolvimento da competência comunicativa. Lochtman e De Boe (2013, p. 144) concordam que as PMs desempenham um papel importante no ensino de ALE, já que seu conhecimento acarreta competências essenciais no contexto da comunicação intercultural.

Assim, além de fazer parte da competência pragmática, ${ }^{2}$ as PMs refletem o domínio da coesão social e interpessoal (relação falante-ouvinte, identidade social, tipo de ato social realizado), no sentido que expressam os papeis dos interlocutores (WEYDT, 2003, p. 20) e refletem a cultura de uma

\footnotetext{
${ }^{2}$ Canale e Swain (1980) integram a competência pragmática como parte sociolinguística da competência comunicativa, definindo-a como "the relationship and interaction between grammatical competence, or knowledge of the rules of grammar, and sociolinguistic competence, or knowledge of the rules of language use" (1980, p. 6). Já Chomsky descreve a competência pragmática como "knowledge of conditions and manner of appropriate use (of the language), in conformity with various purposes” (1980, p. 124).
} 
comunidade (WIERZBICKA, 1991, p. 341). Para Hentschel (2003, p. 57), as PMs atuam como uma espécie de lubrificante para a comunicação, mas se usadas de forma incorreta, também podem ter um impacto negativo sobre a simpatia e cortesia do que é dito. Ainda neste sentido, Kienpointner (2003, p. 144-155) enfatiza que as partículas não necessariamente aumentam a cortesia da conversa, mas podem garantir a atenuação de declarações irônicas.

Segundo a TR, conforme a constante necessidade de seleção na direção do aumento de eficiência, o sistema cognitivo humano estabeleceu-se de tal forma que nossos mecanismos perceptuais tendem automaticamente a escolher estímulos potencialmente relevantes (SPERBER; WILSON, 2005, p. 227). Como as PMs fazem parte do ambiente cognitivo do falante de alemão, ele ou ela usa informações contextuais disponíveis em seu ambiente cognitivo para reconhecer imediatamente o significado pretendido, resultando em uma interpretação que alcance as expectativas de relevância, ou seja, uma relação adequada entre esforço e efeitos cognitivos (AQUINO, 2016, p. 200). Já para os falantes não nativos, como os aprendizes brasileiros, a compreensão da intenção comunicativa das PMs apresenta um desafio, necessitando, então, de maior atenção na metodologia de ensino e nos materiais selecionados.

Zimmerman (1981, p. 116) pondera que aprender uma LE envolve conhecer todo o plano de fundo da vida cotidiana social dessa comunidade linguística, e que existem três etapas para dominar a temática das PMs: primeiro, os aprendizes devem obter a visão de que as PMs são usadas para comunicar certas intenções comunicativas, como expressar expectativas; em segundo lugar, devem entender o seu papel na língua alemã; finalmente, devem identificar o uso correto em termos formais e intencionais. Segundo o autor, ainda há uma fase de consciência, uma fase contrastiva e uma fase de prática de exercícios.

As PMs são extremamente relevantes para o ensino de ALE, já que representam como a língua alemã é de fato utilizada, mas ao mesmo tempo elas manifestam dificuldades de aprendizado, já que o seu significado e função não são facilmente transmitidas (THURMAIR, 2010, p. 3). Além disso, muitas vezes as PMs têm pouco espaço nas aulas de ALE, aparecendo no livro didático em diálogos e textos de leitura, mas raramente são abordadas explicitamente, especialmente nos níveis iniciais. Assim, é importante que a mediação das PMs seja proposta de maneira reflexiva, com 
a qual os aprendizes possam experimentar em um ambiente controlado, para depois utilizá-las livremente na comunicação.

Um dos aspectos que dificultam a aprendizagem destes elementos é a sua dependência contextual, pois o seu significado remete a inferências que vão além da oração, e não existe uma relação 1:1 entre palavra e função (WENZEL, 2002). Devido à sua natureza contextual, as partículas não devem ser tratadas em frases isoladas, mas em exemplos situacionais nos quais as informações precedentes desempenham uma função significativa, para que os alunos consigam imaginar situações específicas (BUSSE, 1992, p. 40). Além da imprecisão semântica, a dificuldade de aprendizagem é reforçada pelas questões sintáticas, como a presença de homônimos em outras classes de palavras (LOCHTMAN; DE BOE, 2013, p. 144).

De acordo com Thurmair (2010, p. 3), além de explorar o significado e a função das PMs de forma estrutural, o seu ensino pode ser abordado por meio de imitação e repetição, de maneira a tornar o aprendizado automatizado. Os aprendizes memorizariam certas frases de exemplos prototípicos (chunks) de uso das PMs, variando o seu contexto. A autora defende que uma mistura entre a compreensão das estruturas cognitiva e a repetição pode ser a melhor solução, ilustrando o significado das PMs através de exemplos típicos e de fácil compreensão. Além disso, Thurmair aponta que treinar usos comuns facilita o aprendizado, oferecendo a oportunidade de trabalhar com as partículas desde o início do aprendizado, sem sobrecarregar os alunos.

As sugestões de ensino de PMs apresentada por Thurmair (2010) corroboram com a perspectiva de Heggelund (2001, p. 8-9), na qual caso o trabalho de descrição gramatical explícito for ineficaz ou complexo, seria aconselhável a aplicação de exercícios voltados à comunicação por intermédio de frases típicas. Nesta doutrina, o ponto de partida da prática didática é uma variedade de ações linguísticas proporcionadas pelo uso de partículas, como surpresa, suposição, contradição e outros. Logo, caso a explicação dos significados das PMs for muito abstrata, deve-se recorrer a descrições dos efeitos gerados no discurso. $\mathrm{O}$ autor aponta ainda que, para tornar a sala de aula um ambiente linguístico fértil, deve-se utilizar métodos modernos de ensino, linguagem natural e tratar um menor número de partículas, mas com todas as suas variantes contextualizadas.

Para Rösler (1982, p. 36), a melhor forma de trazer o assunto da modalidade para a sala de aula é através de um "clima propício para 
partículas". É possível conseguir resultados com a incorporação de explicações, exercícios, e um direcionamento para uma postura independente na sala de aula, sensibilizando o aluno com relação à relevância das PMs e às diferentes formas de uso e significados. $\mathrm{O}$ autor considera importante que se atinja uma determinada qualidade de convívio em sala, permitindo certa interação e um envolvimento afetivo e emocional. Neste sentido, ao planejar as aulas, o professor não pode depender apenas do livro didático, mas deve encontrar outras maneiras de apresentar as PMs para seus alunos, com exemplos contextualizados e em situações comunicativas reais.

Defendemos neste trabalho que as PMs devem ser abordadas já no início da aprendizagem e continuar durante todos os níveis, adaptando as abordagens metodológicas. Nos níveis básicos, as aulas devem ser pautadas nos usos e funções típicas de PMs, através da prática com frases padrões, focando especialmente em PMs mais frequentes. Importante é possibilitar ao aprendiz começar a construir regras e utilizá-las de maneira intuitiva e reflexiva. Em níveis mais avançados é possível apresentar explicações detalhadas e maior número de PMs, assim como a ocorrência em combinação (por exemplo, doch mal,ja wohð). Assim, é possível oferecer regras simples e claras em todos os níveis de aprendizagem, para então treinar o uso em diferentes situações, por meio de atividades com linguagem autêntica.

\section{A aquisição das PMs em ALE: estratégias e soluções didáticas}

Embora com diferentes definições na literatura, fato é que as PMs representam um fenômeno típico da língua alemã e apresentam uma função comunicativa ímpar. Com o seu uso é possível: acarretar o máximo de informação com menor esforço cognitivo (AQUINO, 2016); especificar a relação entre falante e ouvinte (HANSEN, 2006); recuperar contextualmente um acontecimento ou informação anterior à proposição (DIEWALD, 2013); refletir a respeito de questões sociais sobre as particularidades do interlocutor (status, idade, sexo) (WELKER, 1990); disponibilizar informações relevantes para interpretação da mensagem e sinalizar para o ouvinte a necessidade de acessar o seu ambiente cognitivo, o convidando para a interação (SPERBER; WILSON, 2005); negociar inferências entre os interlocutores (LEISS, 2012, p. 39). Portanto, as PMs apresentam uma função comunicativa tão relevante que, por meio delas, podemos modificar e até mesmo criar situações (AQUINO, 2012, p. 90). 
De acordo com Leiss (2012, p. 41), a modalidade pode ser compreendida como meio linguístico que auxilia na negociação de uma representação mental, e as PMs constituem as funções mais complexas da modalidade, pois com elas o falante é envolvido em um design intrincado de negociação dos diferentes ambientes cognitivos (LEISS, 2012, p. 60). As partículas possuem, portanto, uma importante função estratégica de interação, que se encontra por trás do que foi dito. Por meio das PMs, pode-se antecipar a reação do ouvinte, bem como manipular ou guiar uma conversa.

Mesmo ocorrendo mais frequentemente em gênero falado, especialmente em diálogos informais, a utilização das PMs tem crescido de maneira significativa em diferentes meios, como artigos eletrônicos e jornalísticos, propagandas, discurso acadêmico, entre outros. Para Heggelund (2001, p. 3), é indispensável mediar sobre as PMs também com o gênero escrito. Segundo o autor, as PMs wobl e ja ocorrem com grande frequência no discurso escrito, em comparação com, por exemplo, as PMs doch, denn, mal. Na literatura, já é possível encontrar trabalhos que exploram estes elementos em gênero escrito, como a investigação das funções comunicativas das PMs em fóruns na internet (SOUZA, 2008), o estudo com corpus escrito e falado (MÖLLERING, 2001; AQUINO, 2012), e o trabalho de Aquino (2016) investigando o processo em tradução das PMs através de artigos jornalísticos. Independente do gênero escolhido para mediação destes elementos em sala de aula é preciso apresentar exemplos contextualizados e mediar seus aspectos gramaticais e pragmáticos.

Para o ensino das PMs deve-se primeiramente explicitar para o aprendiz de ALE quais são as suas características e as delimitações estruturais. Em alemão as PMs representam uma classe gramatical homogênea, com características sintáticas, semânticas e pragmáticas, que foram desenvolvidas diacronicamente, apresentando um status topológico restrito (ABRAHAM, 1991b, p. 331). Neste sentido, algumas regras básicas podem ser levantadas e discutidas em sala de aula, como: são palavras que não sofrem flexão; não podem ser negadas; não respondem perguntas; podem ser combinadas com outras PMs; não formam um enunciado sozinhas; estão sintaticamente e gramaticalmente integradas na oração; são posicionadas no campo central (Mittelfeld); têm escopo sobre toda a oração; apresentam homônimos não modais em outras categorias; e têm sentido inferencial. 
Uma das questões mais importantes para definir a classe de palavras das PMs se refere aos aspectos topológicos, isto é, sua ocorrência em extensões sintáticas delimitadas, no Mittelfeld ou Campo central (ABRAHAM, 1991b). A divisão por campos (Feld) é uma característica da língua alemã e advém da separação da sentença entre rema e tema. Essa divisão funciona como limites verbais (Saţklammer) que dividem a oração em campos topológicos ocupados por constituintes da frase. As diferentes posições com relação aos limites são: Vorfeld (Campo anterior) que é o campo para a esquerda do limite; Mittelfeld (Campo central) situado dentro dos limites da sentença; Nachfeld (Campo posterior) situado à direita do limite.

QUADRO 1 - Divisão sintática em campos

\begin{tabular}{|c|c|c|c|c|}
\hline $\begin{array}{c}\text { Vorfeld } \\
\text { Position 1 }\end{array}$ & $\begin{array}{c}\text { Linke } \\
\text { Satzklammer } \\
\text { Position } 2\end{array}$ & $\begin{array}{c}\text { Mittelfeld } \\
\text { Satzmitte }\end{array}$ & $\begin{array}{c}\text { Rechte } \\
\text { Satzklammer } \\
\text { Satzende }\end{array}$ & Nachfeld \\
\hline Der Referent, & begann & erst & zu sprechen, & als alle saßen. \\
\hline & Fangen & $\begin{array}{c}\text { Sie doch mit der } \\
\text { Diskussion }\end{array}$ & an, & bitte! \\
\hline
\end{tabular}

Fonte: Hall e Scheiner (2014, p. 286-287).

Há concordância unânime na pesquisa de partículas em que seu significado surge apenas do contexto linguístico e extralinguístico, já que as implicaturas, assim como seu uso, são altamente dependentes do contexto. Para Feyer (1997, p. 69), uma PM pode oferecer um significado inteiramente semântico e pragmático quando usado em um contexto particular. A dependência contextual é um dos principais desafios do ensino e tradução destas palavras, no entanto, a investigação da função nuclear individual de cada partícula e a confrontação com os seus homônimos não modais oferecem soluções para aferir o significado das PMs.

Em uma perspectiva diacrônica, o significado das PMs é derivado, direta ou indiretamente, de seu homônimo de categorias não modais. Segundo Abraham (1991a, p. 209), para obter o significado de uma PM é necessário um processo de reconstrução, que deve contar com uma leitura referencial do elemento lexical homônimo, levando em conta o seu uso no contexto. Para o ensino de PMs em ALE, a justaposição das funções, significados e colocações na oração das partículas contra os homônimos é 
necessária, e oferece ainda uma metodologia adequada para identificação e compreensão do uso destas palavras (BUSSE, 1992, p. 40).

Hentschel e Weydt (2013, p. 289) ${ }^{3}$ oferecem uma análise comparativa entre a PM e a conjunção aber, na qual a conjunção tem a função de ligar dois elementos x e y, de x pode variar uma sequência z que não é verdade, como "Ellen ist klein, aber stark", ${ }^{4}$ isto é, pelo seu tamanho (x) imagina-se que ela não teria força (z), mas não é verdade, ela é forte (y). A PM abernão apresenta a função de ligar elementos da frase, mas tem escopo na oração toda, além disso, elas se posicionam no campo central e não são separadas por vírgula, como é possível observar no exemplo "Ihr seid aber groß geworden". ${ }^{5}$ Uma análise contextual poderia indicar que a última vez que o falante viu a criança ela era pequena, então em sua memória ela não era grande. A PM aber indica uma surpresa com relação não apenas ao fato que a criança cresceu, já que isso seria esperado, mas quão crescida ela está.

A análise das PMs também deve ser pautada nas funções nucleares específicas de cada uma delas, que se mantém em todas as suas ocorrências. Logo, nos pautamos na abordagem minimalista, que defende que o significado das PMs não pode ser acessado apenas consultando uma lista de palavras, sem distinções baseadas em parâmetros semântico-lexical de cada PM em seu contexto de uso (ABRAHAM, 1991a, p. 208), mas sim investigando a sua função específica, juntamente com a análise contextual.

Assim, tanto para a prática didática como para a procura por equivalentes funcionais em outro idioma, recomenda-se a investigação do significado destes elementos em um nível mais geral. A discussão da função nuclear das PMs pode ser abordada em todos os níveis de conhecimento em

\footnotetext{
${ }^{3}$ Os autores apresentam ainda outros exemplos de comparação entre as PMs e seus homônimos, como: "Er kennt der Mörder, denn er hat die Tat gesehen" (Ele sabe quem é o assassino, pois ele viu o ato) (conjunção) - "Wie heißt du denn?" (Como é que você se chama?) (PM); "Alles war still, doch dann ging das Gewitter los" (Tudo estava em silêncio, mas então a tempestade começou) (conjunção) - "Das musst du doch zugeben!" (Mas você tem que admitir isso) (PM); "Kommst du? - Ja" (Você vem? - Sim. (partícula de resposta) - “Hau ja ab!” (Vaza!) (PM); "Es war (ein)mal ein kleines Mädchen” (Era uma vez uma menininha) (advérbio) - "Komm mal her!" (Vem aqui!) (PM); "Ich fühle mich wohl' (Eu me sinto bem) (advérbio) - "Wer hat das wobl geschrieben?” (Quem será que escreveu isso?) (MP).

${ }^{4}$ Hellen é pequena, mas grande.

${ }^{5}$ Nossa, mas como vocês cresceram!
} 
ALE, e pode ser vinculada com tarefas contrastivas com a língua portuguesa. Apresentamos a seguir as funções nucleares das PMs aber, denn, doch, eigentlich, ja e wohl:

(i) Aberindica surpresa, que a realidade é diferente da esperada. A surpresa está relacionada à extensão dos fatos (HENTSCHEL; WEYDT, 2013, p. 286). Na frase "Die Modalpartikeln sind aber interessant!", 6 o falante poderia imaginar que as partículas modais eram interessantes, mas não nessa proporção. Além disso, a PM aber pode expressar um significado pragmático, como no comentário sobre as habilidades culinárias de alguém, "Du kannst aber kochen"7 que pressupõe surpresa, mas também um elogio, ou até ironia (WEYDT, 2006, p. 13).

(ii) Denn ocorre geralmente em perguntas, indica que o conteúdo da sentença aponta para algo que pode ser encontrado em um contexto anterior. Em um uso típico da PM denn, "Wie heißt du denn?", ${ }_{8}$ o falante pressupõe que, por meio de informações contextuais (algo que aconteceu ou foi dito anteriormente), o seu interlocutor sabe a resposta ou tem algo relevante a dizer sobre aquilo.

(iii) Doch pressupõe um componente semântico de adversidade ou contradição no sistema inferencial do ouvinte (HENTSCHEL; WEYDT, 1983, p. 269). No exemplo "Der soll mich nach Hause fahren? Der ist doch betrunken!", ' o falante identifica que o ouvinte não levou em consideração ou não sabe sobre alguma informação relevante para a troca comunicativa, ou seja, estar embriagado torna o ato de dirigir inviável (pela lei e conhecimento comum).

(iv) Ja pressupõe concordância ou conhecimento mútuo entre os interlocutores e também pode indicar surpresa. No exemplo "Die Katze ist ja schon gefüttert worden", ${ }^{10} \mathrm{o}$ falante utiliza a PM $j a$, pois sabe ou imagina que o seu interlocutor concorda ou sabe sobre tal informação. A PM ja também pode indicar uma surpresa, como em "Der Kaffe ist

\footnotetext{
${ }^{6}$ Mas como as partículas modais são interessantes!

${ }^{7}$ Mas como você cozinha bem!

${ }^{8}$ Como é que você se chama?

${ }^{9}$ Ele vai me dar carona pra casa? Mas ele está bêbado!

${ }^{10} \mathrm{O}$ gato já foi alimentado né.
} 
ja heiß!", ${ }^{11}$ mas diferentemente da PM aber, ja indica surpresa que aquilo de fato aconteceu, o falante não esperava que o café estivesse quente, mas sim pronto para beber (WEYDT, 2006, p. 13).

(v) Eigentlich, semelhante a denn, retoma uma informação contextual imediata; é utilizada em orações interrogativas, demonstra o interesse do falante e que o ouvinte sabe a resposta ou tem algo relevante a dizer. Além disso, essa PM eigentlich sinaliza uma mudança de tópico ou assunto (mas não completamente). O contexto não irá mudar, apenas o aspecto sob o qual o contexto é considerado. Em "Wie heißt du eigentlich", ${ }^{12}$ entende-se uma mudança de assunto ou início de um novo tópico.

(vi) Wobl tem a função de sinalizar suposição, hipótese ou menor comprometimento com a proposição (AQUINO; ARANTES, no prelo). Na declaração, "Er wird Cordle wohl am Montag wegen fahrlässiger Tötung anklagen", ${ }^{13}$ o falante supõe que Cordle será indiciado na segunda-feira. Podemos imaginar que a ação foi cometida no final de semana, então as medidas devem ser tomadas o mais rápido possível, já que o ocorrido é um assassinato. Outra alternativa seria que o falante não quer se comprometer, pois não tem certeza, ou não quer oficializar a notícia.

Consideramos essa abordagem adequada para o ensino de ALE, pois mesmo com um número limitado de partículas, é possível abordar todas as suas funções e delimitações através de diferentes exemplos, que podem ser identificados e treinados em sala de aula. Apresentamos a seguir um esquema das PMs selecionadas, suas funções nucleares e exemplos. O desenvolvimento de quadros promete uma melhor assimilação do conteúdo apresentado. Além disso, sugerimos a discussão das interpretações destas PMs para o português, introduzindo os aspectos modalizadores na língua portuguesa.

\footnotetext{
${ }^{11}$ Como esse café está quente, né?

${ }^{12}$ Então como você se chama?

${ }^{13}$ Ele deve indiciar Cordle na segunda-feira por homicídio culposo.
} 
QUADRO 2 - PMs, sua função nuclear, exemplos e equivalentes funcionais em português

\begin{tabular}{|c|c|c|c|}
\hline PMs & Função nuclear & Exemplo & $\begin{array}{c}\text { Equivalentes em } \\
\text { português }\end{array}$ \\
\hline Doch & $\begin{array}{l}\text { Adversidade, } \\
\text { contradição. }\end{array}$ & $\begin{array}{l}\text { Der soll mich nach } \\
\text { Hause fahren? Der } \\
\text { ist doch betrunken! }\end{array}$ & $\begin{array}{l}\text { Então, mas, aí, lá, } \\
\text { bem (que), sim. }\end{array}$ \\
\hline $\mathrm{Ja}$ & $\begin{array}{l}\text { Concordância, } \\
\text { conhecimento comum, } \\
\text { surpresa. }\end{array}$ & $\begin{array}{l}\text { Die Katze ist } j a \\
\text { schon gefüttert } \\
\text { worden. }\end{array}$ & É que, sim, mas, né. \\
\hline Wohl & $\begin{array}{l}\text { Suposição, hipótese, } \\
\text { menor } \\
\text { comprometimento. }\end{array}$ & $\begin{array}{l}\text { Er wird Cordle wohl } \\
\text { am Montag wegen } \\
\text { fahrlässiger Tötung } \\
\text { anklagen. }\end{array}$ & $\begin{array}{l}\text { Deve, parece que, } \\
\text { bem (que). }\end{array}$ \\
\hline Aber & $\begin{array}{l}\text { Surpresa, a realizada é } \\
\text { diferente da esperada, } \\
\text { surpresa sobre a } \\
\text { extensão dos fatos. }\end{array}$ & $\begin{array}{l}\text { Die Modalpartikeln } \\
\text { sind aber } \\
\text { interessant! }\end{array}$ & $\begin{array}{l}\text { Mas, é que, bem } \\
\text { (que). }\end{array}$ \\
\hline Denn & $\begin{array}{l}\text { Aponta para algo que } \\
\text { poder ser encontrado } \\
\text { em um contexto } \\
\text { anterior, o ouvinte sabe } \\
\text { a resposta. }\end{array}$ & Wie heßt du denn? & $\begin{array}{l}\text { Mesmo, aí, lá, } \\
\text { então, é que. }\end{array}$ \\
\hline
\end{tabular}

Fonte: Elaborado pelo autor.

Além disso, análises contrastivas são recomendadas para o ensino de PMs. Neste sentido, a comparação entre orações (com e sem PM ou entre diferentes PMs) são relevantes, pois proporcionam analogias claras sobre a função comunicativa das PMs. Para a comparação entre orações com e sem PM, utilizaremos alguns dos exemplos apresentados no trabalho de Heggelund (2001, p. 6). O autor sugere que o significado das PMs é facilmente demonstrado pela comparação de frases contendo partículas com os conjuntos correspondentes livres delas, como nos exemplos do Quadro 3: 
QUADRO 3 - Comparação de ferramentas de ensino de PMs

\begin{tabular}{|c|c|}
\hline Das war aber eine Reise ${ }^{14}$ & Das war eine Reise \\
\hline Bist du denn fertig? ${ }^{15}$ & Bist du fertig? \\
\hline Wie war doch ihr Name? ${ }^{16}$ & Wie war ihr Name? \\
\hline Es regnet $j a .^{17}$ & Es regnet. \\
\hline Du bist wobl $^{16}$ verrückt! ${ }^{18}$ & Du bist verrückt! \\
\hline
\end{tabular}

Fonte: Heggelund (2001, p. 2).

Os exemplos oferecidos acima podem ser debatidos em sala de aula através da análise em diferentes contextos e situações comunicativas. A oração "Das was eine Reise", ${ }^{19}$ por exemplo, informa que uma viagem aconteceu, sem informações adicionais. Já, "Das war aber reine Reise”, a PM traz consigo uma dependência contextual, indicando surpresa com relação à extensão dos fatos. Se a viagem foi muito boa poderíamos interpretar em português com o modalizador mas, “Mas que viagem!”.

Sugerimos ainda a comparação entre diferentes PMs em uma mesma oração, como nos exemplos encontrados em Duden (2016, p. 604):

(1) Der Vortrag war $j a$ interessant! ${ }^{20}$ (Esperava-se uma palestra desinteressante).

Der Vortrag war aber interessant! (Esperava-se uma palestra menos interessante).

\footnotetext{
${ }^{14}$ Mas que viagem!

${ }^{15}$ Então, você está pronto?

${ }^{16}$ Como é mesmo o seu nome?

${ }^{17}$ Está chovendo, né.

${ }^{18}$ Você só pode ser louco!

${ }^{19}$ Isso foi uma viagem!

${ }^{20}$ A palestra foi interessante.
} 
(2) Ich kann nicht kommen, ich habe ja Besuch. ${ }^{21}$ (Como você já sabe). Ich kann nicht kommen, ich habe doch Besuch. (Como você não sabe, ou como você se esqueceu).

No exemplo (1), a PM ja indica que se esperava uma palestra ruim ou monótona. Assim, voltamo-nos à interpretação "que" algo é uma surpresa. Já a PM aber pressupõe que era esperado uma palestra interessante, mas não tanto, ou seja, tem a ver com a extensão dos fatos, o "quanto ou como" algo é surpreendente. Em (2) a PM ja cumpre a função de indicar que algo é conhecido ou aceito pelos interlocutores. No caso da PM doch ou o ouvinte não tinha conhecimento ou não levou em consideração o fato mencionado pelo falante, ou seja, que receberia visita.

Os exemplos mencionados acima podem ser ensinados, especialmente em níveis iniciais, através de chunks, usos típicos, podendo, portanto, servir como modelo de linguagem para a prática didática e então ser reproduzidas na comunicação. Neste sentido, atividades de treinamento através de repetição e interpretação podem ser úteis e interessantes para a prática e discussão. Não obstante, a função metacomunicativa das PMs também deve ser investigada em contraste com as expressões de modalidade na própria língua nativa dos alunos, fazendo com que eles se conscientizem de seu uso e significado (BUSSE, 1992, p. 30-32). Ainda, as atividades contrastivas devem considerar a análise contextual, a relação entre os interlocutores (intenções e expectativas) e a função comunicativa específica de cada PM.

A questão sobre os equivalentes funcionais para as PMs é abordada há muito tempo em estudos de teoria de tradução, começando com o trabalho seminal de Weydt (1969). Contudo, nos últimos anos têm-se dado especial atenção à investigação sobre a existência de PMs em línguas que, incialmente, eram consideradas sem a possibilidade de apresentar esta classe de palavras. Mesmo com a constante divergência na área, os trabalhos parecem concordar que, embora exista uma evidente diferença de classificação, é difícil conceber que as funções comunicativas das PMs sejam restritas a línguas particulares (WALTEREIT; DETGES, 2007, p. 1391). Vejamos alguns exemplos de modalidade em português, interessantes para a mediação contrastiva com as PMs:

${ }^{21}$ Eu não posso ir, vou receber visita. 
(3) Mas: Mas que viagem! (Das war aber eine Reise!)

(4) Ai: Pense nisso aí. (Denk mal drüber nach.)

(5) Então: Mas o que você fez hoje então? (Was hast du denn heute gemacht?)

(6) Bem: Bem que eu sabia! (Ich habe es wohl gewußt!)

(7) Lá: Eu vou lá saber a idade dele. (Woher sol ich denn sein alter wissen?)

Assim, apresentamos no Quadro 4 algumas sugestões dos equivalentes funcionais em português, que devem ser trabalhadas levando em consideração o contexto de uso. Como mencionado anteriormente, tabelas e quadros podem ser ferramentas relevantes para a mediação de PMs, pois apresentam informações de maneira objetiva, permitindo a reconstrução dos exemplos, contextos e intenções comunicativas das partículas.

QUADRO 4 - PMs em alemão e em português

\begin{tabular}{|c|c|}
\hline PM (alemão) & PM (português) \\
\hline Setz dich doch. & Senta $a \imath$. Senta (ai) vai. \\
\hline Ich habe doch gesagt! & Bem que eu avisei! Mas eu avisei! \\
\hline Das ist doch zu viel! & Mas isso é demais! $A \hat{i}(j a)$ é demais! \\
\hline Du musst doch essen! & Mas você tem que comer. Vai comer sim. \\
\hline Aber das ist doch nicht möglich. & Mas isso lá é possível. \\
\hline Denk mal drüber nach. & Pense nisso aí. Pense nisso vai. \\
\hline Ich habe es wohl gewußt! & Bem que eu sabia! \\
\hline So, dafür hast du wobl den großen Stock da? & $\begin{array}{l}\text { É para isso que você tem esse pedaço de pau } \\
\text { enorme aí então? }\end{array}$ \\
\hline Das war aber eine Reise! & Mas que viagem! \\
\hline Das Wasser ist aber warm! & Mas que água quente! \\
\hline Das ist aber ein Auto! & Mas isso sim é um carro! \\
\hline Das ist aber heiß! & Mas que quente! Isso sim é quente! \\
\hline Das ist $j a$ heiß! & Está quente mesmo ne. Tá quente bein! \\
\hline Ich habe es ja verdient! & Eu bem que mereci! Mas eu mereci ne? \\
\hline Was hast du denn heute gemacht? & Mas o que (que) você fez hoje então? \\
\hline Woher sol ich denn sein Alter wissen? & Eu vou lá saber a idade dele. \\
\hline
\end{tabular}

Fonte: Elaborado pelo autor. 
Na próxima seção discutiremos sugestões práticas de atividades para ALE, que podem englobar as considerações apresentadas acima. Os materiais suportam a mediação em todos os níveis de conhecimento, desde que as PMs sejam abordadas refletindo sobre os aspectos gramaticais e pragmáticos. Ainda, os materiais selecionados (filme e quadrinhos) permitem um aprendizado reflexivo e autônomo. O ensino e aprendizagem de elementos modais, como é o caso das PMs, dependem diretamente da compreensão e uso em diferentes situações comunicativas, assim, sua aprendizagem não pode ser restrita apenas à sala de aula.

\section{Materiais}

A temática das PMs em ALE é desafiadora por inúmeros motivos, entre eles o seu significado, sua classificação e também as diferentes metodologias e perspectivas de pesquisa e ensino. Ainda existe uma grande lacuna quando se trata de investigações sobre práticas didáticas para a mediação de PMs. Portanto, temos o intuito principal de apresentar sugestões relevantes para o ensino das PMs em ALE. Não realizamos uma análise dos livros didáticos, no entanto, ele também é considerado como uma ferramenta importante para a mediação destas palavras, exigindo, porém, uma análise atenta do professor de seu conteúdo e limitações.

Como já mencionado, os aprendizes podem assimilar as PMs de maneira intuitiva, mas é essencial o desenvolvimento de explicações e materiais adequados para o reconhecimento das funções comunicativas e classificação gramatical destas palavras modais. Assim, a escolha do material é muito importante para a mediação das PMs, pois precisa incentivar a comunicação e proporcionar um ambiente aberto e criativo. Não obstante, recomenda-se que os professores trabalhem conjuntamente com os aprendizes, para explorar diferentes atividades e ferramentas, fomentando um aprendizado autônomo e inclusivo para a compreensão da língua.

Diferentes tarefas, atividades e projetos podem ser aplicados para este fim. Em especial, são sugeridos materiais autênticos. A reflexão sociocultural também pode ser adaptada ao ensino de PMs. O ensino através de filmes e quadrinhos procura criar um clima adequado para a aprendizagem de PMs, abrangendo as suas funções comunicativas e significados tanto na linguagem escrita como na falada. 


\subsection{Filmes}

A utilização de filmes traz diversos benefícios para o aprendizado de LE, desenvolvendo diferentes habilidades e estratégias de aprendizagem. Através de uma abordagem lúdica, com histórias, contextos e personagens (NAPOLITANO, 2003), é possível mediar inúmeros aspectos de língua e cultura alvo.

Para o ensino de PMs, este material é bastante eficiente, pois apresenta linguagem autêntica permeada por contextos específicos, possibilitando ao aluno uma melhor compreensão do uso e função destes elementos. Diferentes projetos podem ser aplicados dentro desta temática, como a discussão de filmes, análise e sugestão de legendas, desenvolvimento de pequenos vídeos com continuação de alguma cena, oferecimento de um fim alternativo, entrevista com algum personagem, roleplay, entre outros. Os alunos também podem ser responsáveis por sugerir filmes, convidando assim, o aprendiz a participar da escolha de materiais.

Com a intenção de investigar as funções comunicativas das PMs doch e ja, Aquino (2012) empregou um corpus constituído de quatro filmes alemães, tendo em vista as possibilidades de tradução para o português brasileiro através da análise reflexiva do contexto apresentado. Levando em consideração as consequências para o ensino de ALE, o trabalho discute as legendas oferecidas pelos filmes e as sugestões de traduções apresentadas por seis entrevistados. A autora conclui que a investigação do significado das PMs pode ter implicâncias interessantes quando analisadas através de filmes, já que oferecem contextos específicos, apontando a relação entre os interlocutores, a entonação, a intenção comunicativa e as expectativas do ouvinte.

O corpus constituído de filmes permite, portanto, verificar a frequência do uso das partículas na comunicação de maneira contextualizada. Os filmes se aproximam da linguagem oral e real do alemão, incluindo não apenas o esquema linguístico, mas também o extralinguístico e a aproximação da cultura e sociedade. Os trechos dos diálogos e as diferentes situações de fala podem ser utilizados em sala de aula, enriquecendo os estudos de língua alemã. Assim, apresentaremos a seguir opções de mediação das PMs doch e $j a$ através de dois trechos dos filmes Das Leben der Anderen (A vida dos outros - 2006), do diretor Florian Henckel von Donnersmarck e Good Bye Lenin (Adeus, Lenin-2001/2003) do diretor Wolfgang Becker. 
Dependendo do nível de conhecimento, os trechos podem ser apresentados sem legenda, onde os estudantes seriam incentivados a discutir, por meio da análise contextual, o significado das PMs tendo em vista a sua função nuclear, aspectos gramaticais e os possíveis equivalentes em língua portuguesa. Esta atividade pode ser realizada em grupos de discussão ou através de um questionário escrito. Para turmas iniciais sugerimos divulgar a legenda do filme e então, com o conhecimento adquirido sobre as PMs, discutir a validade dessa tradução, oferecendo sugestões. Outra opção seria oferecer uma lista de possíveis equivalentes ou interpretações em português, para que os estudantes escolham qual opção seria mais adequada para aquele contexto. Além disso, em turmas avançadas pode ser debatido a diferença entre as PMs e seus homônimos através dos aspectos gramaticais e semânticos. Finalmente, após as atividades propostas, o professor deve mediar as discussões, relembrando os aspectos gramaticais e pragmáticos de cada PM apresentada.

Como mencionado anteriormente, além do conhecimento da função nuclear de cada partícula, é essencial a análise contextual para a compreensão do significado e intenção comunicativa das PMs. Assim, o professor pode discutir as cenas dos filmes, a fim de acessar a intenção comunicativa das PMs em cada contexto. Apresentamos a seguir duas sugestões de trechos de filmes com as PMs doch e $j a$, a análise contextual e a elucidação das funções de doch e ja para serem trabalhados em sala de aula.

\section{Trecho I (Das leben der anderen):}

13'17': Ministro: Ich darf doch?

Legenda do filme: Posso?

\section{Informações contextuais do trecho I:}

Os personagens (Georg, Christa e o ministro) estão em uma festa comemorando a peça dirigida por Georg, tendo sua namorada, Christa, como estrela principal. O casal dança. $\mathrm{O}$ ministro, um poderoso e autoritário político da Alemanha comunista, que tem interesse em Christa, aproxima-se e pede a Georg para dançar com a atriz, proferindo a oração do trecho I. Ao utilizar a PM doch, o ministro não realiza um pedido, mas sim afirma, que mesmo a desgosto de Georg, dançaria com Christa.

A partir da análise contextual, e da função de doch,é possível estabelecer que a proposição expressada indica uma ênfase provocativa, irônica e até 
ameaçadora por parte do personagem, reforçando a inferioridade de Georg perante um oficial do governo neste momento político. Como mencionamos anteriormente, a PM doch tem um componente semântico de adversidade ou contradição no sistema inferencial do ouvinte. Logo, esta PM vincula um ato de fala intencional, confirmando, mesmo com a contradição, isto é, o desagrado e irritação do casal, que o ministro vai realizar a ação.

Essa oração poderia ser interpretada em português como "Posso, não?", ou com o uso de mas e né com função modal, "Mas eu posso, nê". Essas alternativas em língua portuguesa se aproximam da intenção comunicativa de doch neste contexto, ou seja, indicar uma contradição e ironia, podendo, portanto, auxiliar na compreensão e ensino desta palavra modal em alemão.

Trecho II (Good bye Lenin):

23':17" Alex: Aber du kennst sie ja.

Legenda do filme: Sabe como ela é.

\section{Informações contextuais do trecho II:}

Christiane, mãe de Alex e Ariane, está em coma no hospital. A enfermeira toca uma fita que Alex gravou para fazer companhia à mãe, nos momentos em que não pode visitá-la pessoalmente. Durante a mensagem Alex diz que sua irmã não quis falar nada na fita por achar besteira, e justifica com a oração do trecho II. A PM ja pressupõe concordância ou que algo é de conhecimento dos interlocutores. Logo, Alex assinala que a mãe conhece a filha, e entende por que ela não quis participar da gravação. O conhecimento compartilhado agrega-se, neste contexto, ao fato de que Ariane é rebelde crítica e egoísta. Assim, para os personagens, a falta de atenção e interesse dela não seria novidade, mas sim uma atitude esperada.

Finalmente, esta oração poderia ser interpretada como "Mas bem que você a conhece", possibilitando ao professor abrir espaço para a discussão sobre as funções modais de bem ou bem que em português como equivalentes funcionais da PM ja neste contexto.

Filmes, séries, novelas e vídeos (por exemplo, do You'Tube), oferecem, portanto, contextos específicos para o ensino das PMs. Levar a análise dos filmes para a sala de aula torna a aprendizagem de ALE dinâmica e agradável, abrangendo não somente as PMs, como também o estudo da sintaxe, semântica, pragmática e cultura do idioma estudado. Além disso, estas atividades viabilizam um clima propício às partículas, direcionando o 
aluno a uma possível postura independente em sala de aula. Neste sentido, os estudantes podem desenvolver a aprendizagem autônoma, assistindo filmes e vídeos de seu interesse, procurando identificar as PMs, seu significado e função comunicativa em cada contexto.

Para as atividades com cinema envolvendo a mediação das PMs em ALE, sugerimos ainda os seguintes filmes: Good Bye Lenin (Adeus, Lenin2001/2003); Das Leben der Anderen (A vida dos outros - 2006); Die fetten Jahre sind vorbei (The Edukators - 2004); Lola rennt (Corra Lola, corra - 1997/1998); Die Welle (A onda - 2008); e Fack ju Göbte - 1, 2, 3 (2013, 2015, 2018).

\subsection{Quadrinhos}

O gênero textual de histórias em quadrinhos representa um recurso pedagógico facilitador para o processo de ensino aprendizagem de ALE. Por meio de imagens e texto, os quadrinhos oferecem diferentes características do discurso e reflexão sobre aspectos culturais, abordando também as habilidades de leitura, oralidade, escrita e argumentação (CARY, 2004, p. 24). Assim, os quadrinhos devem ser considerados para o desenvolvimento das competências comunicativas, como a mediação das PMs.

Os quadrinhos podem ser aplicados de diversas formas em sala de aula. Apresentaremos a seguir uma sugestão de atividade que foi desenvolvida com a turma de Língua Alemã II da Universidade de São Paulo (USP). Após a mediação dos aspectos gramaticais, pragmáticos e a função nuclear das PMs selecionadas (as mesmas introduzidas neste trabalho), a professora aplicou diferentes atividades sobre este tema, como música, vídeos do YouTube, textos, propagandas, análise do livro didático e quadrinhos. Com os quadrinhos, os alunos deveriam primeiramente, sozinhos ou em grupos, compreender a história em alemão. Em um segundo momento, eles precisavam identificar as PMs e interpretar o seu significado através da análise contextual. Finalmente, os aprendizes deveriam oferecer sugestões de interpretação em português para o texto dos quadrinhos.

Esta atividade foi proveitosa, já que os alunos conseguiram identificar as PMs, indicar a sua função e significado no contexto. Porém, eles apresentaram dificuldade em sugerir uma interpretação para o português, indicando ser necessário uma mediação específica sobre a modalidade em língua portuguesa. No entanto, a discussão em sala permitiu uma maior reflexão, tanto sobre a função e significado no contexto das PMs, como dos possíveis equivalentes em português. Ainda, vale ressaltar que os estudantes 
se interessaram pelas atividades com quadrinho, incentivando-os a procurar outras histórias como tarefa, e então apresentar opções contendo PMs para os colegas.

Além da mediação das PMs através da leitura e interpretação das histórias, o professor pode convidar os alunos a desenvolverem os próprios quadrinhos. Logo, a simbiose entre imagem e texto auxiliaria na compreensão do significado, intenção e informações contextuais das PMs. Assim, este gênero permite criar um clima favorável ao ensino de PMs e a aplicação de diferentes atividades didáticas.

Vejamos na Figura 1 os exemplos de quadrinhos aplicados em sala de aula de Língua Alemã II, juntamente com a análise contextual, da função das PMs eigentlich, doch mal, wohl, denn, aber e as sugestões de interpretação para a língua portuguesa.

FIGURA 1 - Quadrinho Haiopeis (919), do autor Thomas Siemensen
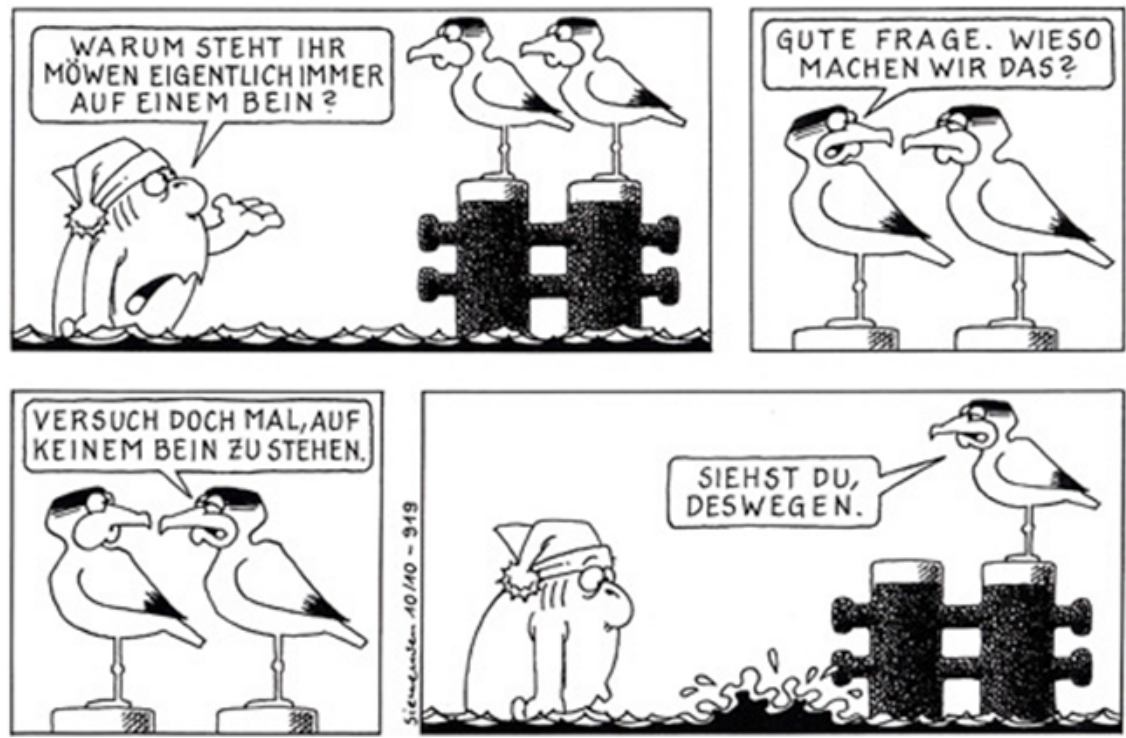

As PMs encontradas neste quadrinho são: eigentlich e doch mal em coocorrência. Como vimos anteriormente, a PM eigentlich indica uma ligação contextual direta, em que o ouvinte sabe a resposta ou tem algo relevante a dizer e uma mudança de tópico ou assunto. Logo, com "Warum steht ihr Möwen eigentlich immer auf einem Bein?”, o tubarão inicia um novo tópico, as gaivotas sabem (ou devem saber) a resposta, pois se relaciona a algo da 
vida delas, e indica uma ligação contextual imediata, isto é, ele está vendo elas na posição curiosa (com uma perna só) naquele momento. A oração poderia ser interpretada como, "Por que é que vocês gaivotas ficam paradas com uma perna só?", ou, "Mas viu, por que é que vocês [...]".

A segunda oração com PM, "Versuch doch mal auf keinem Bein zu stehen" permite a mediação sobre o uso em combinação das PMs. A coocorrência doch mal é bastante comum, inclusive nos livros didáticos, assim, ela pode ser ensinada como chunks, ou seja, sequências frequentes na língua. Existem regras específicas de combinação das PMs, mas uma das questões principais é saber que cada PM mantém a sua função nuclear e, a primeira PM da sequência tem um papel central no significado. A PM doch tem a função de contradição; neste caso, a gaivota indica que a sua companheira não considerou tentar ficar sem nenhuma perna. Já a PM mal tem função de convencimento, incentivando o interlocutor a fazer algo. Juntas elas têm a intenção de convencer o ouvinte a fazer algo que não tinha pensado antes, neste caso, ficar de pé sem nenhuma perna. Assim, poderíamos interpretar esta oração com o uso modal de aí e então no português: "Tenta aí ficar em pé sem nenhuma perna então".

Vejamos na Figura 2 mais um exemplo de quadrinho, com as PMs wohl e denn e as sugestões de interpretação para a língua portuguesa.

FIGURA 2 - Quadrinho Haiopeis (074), do autor Thomas Siemensen
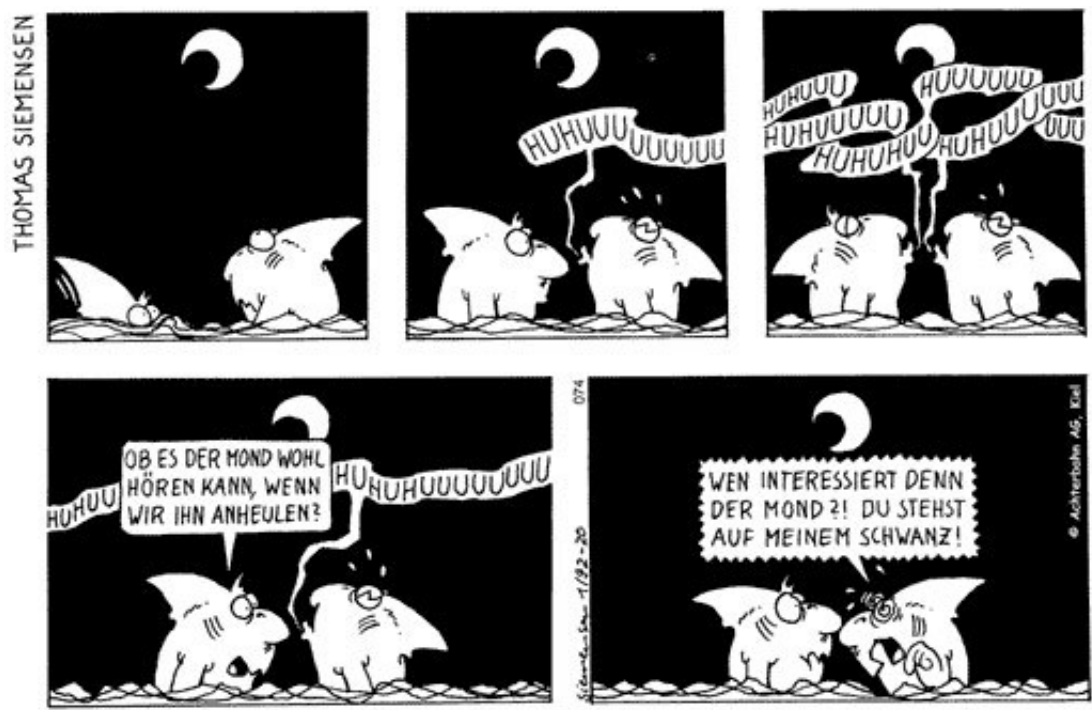
As PMs encontradas neste quadrinho são: wobl e denn. A PM wobl tem função de hipótese, suposição ou baixo comprometimento com a proposição. Então, com "Ob es der Mond wobl hören kann [...]" o falante questiona se existe a possibilidade que a lua escute os uivos. Com a PM wobl neste contexto, o falante apresenta a suposição que este seria o motivo pelo qual eles estavam emitindo tal som, ou seja, para a lua ouvir. Pensando que lobos costumam uivar para a lua, e os personagens são dois tubarões, o uso de wohl teria a função de veicular uma hipótese plausível para a estranha atitude dos animais. Assim, sugerimos a seguinte interpretação da oração e contexto para o português: "Mas será que a lua deve ouvir [...]?".

$\mathrm{Na}$ frase, "Wen interessiert denn der Mond?", a PM denn pressupõe que o conteúdo da sentença aponta para algo que pode ser encontrado em um contexto anterior, aqui eles haviam acabado de falar sobre a lua e os uivos. A oração poderia ser interpretada como, "Mas quem é que está ligando pra lua?”, ou "Quem está lá ligando para a lua”, indicando também a surpresa, com relação ao comentário anterior do personagem com PM wobl, e a indignação da falta de percepção do colega que estava pisando na sua cauda.

Este último quadrinho apresenta a análise das PMs aber e denn e, sua interpretação para a língua portuguesa.

FIGURA 3 - Quadrinho Haiopeis (387) do autor Thomas Siemensen
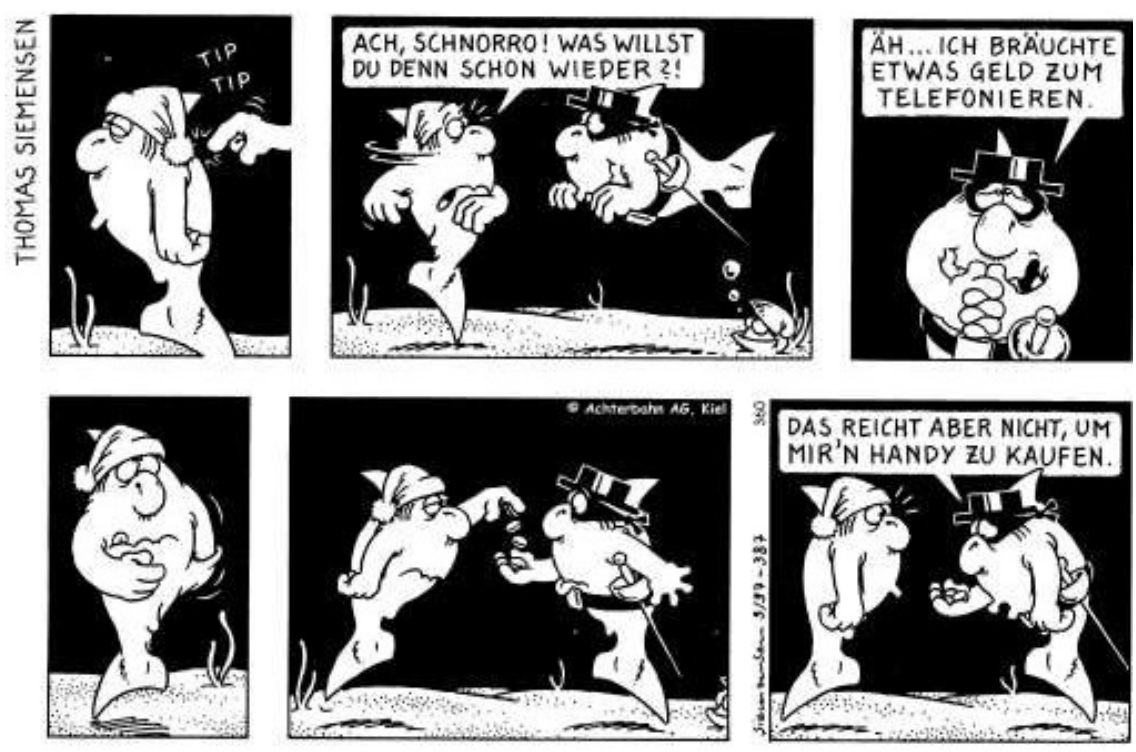
As PMs encontradas neste quadrinho são: denn e aber. Como a função da PM denn já foi discutida no exemplo anterior, apresentamos apenas a interpretação de "Was willst du denn schon wieder?, como "O que é que você está querendo de novo?".

A PM aber tem a função de sinalizar uma surpresa com relação à extensão dos fatos e, que a realidade é diferente da esperada. Logo, "Das reicht aber nicht [...]" indica a insatisfação do personagem com relação à quantidade de dinheiro dada pelo amigo, ou seja, é menos que esperava e insuficiente para comprar um celular. Para a interpretação poderíamos utilizar mas com função modal, "Mas isso não é suficiente [...]". Assim como em alemão, essa palavra se diferencia do seu homônimo de conjunção. Neste sentido, como demonstrado na seção 3, o professor pode aproveitar esses exemplos para diferenciar a classe de palavras das PMs e seus homônimos não modais, tanto em alemão, como em português.

Finalmente, a mediação de PMs, assim como de outros elementos linguísticos e interculturais, por meio de quadrinhos parece ser interessante, pois esse gênero apresenta linguagem acessível, histórias curtas e engraçadas, são acompanhados de imagens que auxiliam na compreensão e representam um material familiar aos alunos. Além disso, os quadrinhos apresentam símbolos concretos (sequências de sons, letras ou palavras) servindo como pistas para que o leitor complete as informações a partir de suas experiências, do seu conhecimento e da língua em questão (MEIRELES, 2007, p. 158). Então, trabalhar com este gênero permite vincular uma linguagem contextualizada, com informações implícitas e explícitas. Ainda neste sentido, as histórias possuem grande ocorrência de PMs e contextos de uso, facilitando o trabalho do professor.

\section{Conclusão}

As PMs são recursos linguísticos imprescindíveis na língua alemã, que devem ser constantemente incluídas no ensino de ALE. Os estudantes da língua alemã, quando não incorporam as partículas, tornam-se falantes atípicos do alemão, que não compreendem nuances essenciais para a troca comunicativa na língua estudada. Além disso, elas são essenciais para a interação e comunicação intercultural e, fomentam as habilidades pragmáticas da língua. A este respeito, o uso de PMs pode desempenhar um papel essencial no ensino ALE (WEYDT, 2003, p. 21). 
Para Weydt (2003, p. 13) a mediação das PMs em ALE deve ser feita levando-se em consideração as necessidades dos estudantes, como o nível de conhecimento, quão relevante é sua aprendizagem, o interesse pessoal, qual o uso da LE e quais exercícios e materiais devem ser aplicados para uma mediação motivadora. A escolha do material didático é, portanto, de grande importância e deve abarcar diferentes usos e inferências contextuais necessárias para a interpretação destas palavras. O livro didático também precisa ser avaliado, apurando como os exemplos e exercícios podem ser trabalhados em sala de aula. De maneira geral, o nível de detalhamento da explicação precisa estar pautado no interesse e conhecimento prévio do aluno.

Não obstante, é essencial o incentivo da aprendizagem autônoma e reflexiva, para que os alunos reconheçam o uso e o significado das PMs na comunicação, assim como os aspectos culturais e sociais vinculados às questões pragmáticas, despertando, assim, a curiosidade da língua e cultura alemã. Neste sentido, situações de uso autênticos são de extrema importância na mediação das PMs. Consequentemente, a dificuldade de aquisição destes elementos pode ser superada com o emprego de estratégias didáticas, que levem em conta as questões gramaticais e pragmáticas através da análise contextual, a função nuclear, a diferenciação dos seus homônimos, a relação comunicativa entre os interlocutores e pela análise contrastiva.

Mesmo com diversas investigações acerca das PMs, ainda pode-se observar uma lacuna em pesquisas voltadas às questões didáticas e de mediação destes elementos em ALE. Sugerimos, portanto, uma descrição focada nas regras e funções comunicativas para auxiliar professores e aprendizes a desvendarem o seu significado e uso no discurso. Neste sentido, tivemos a intenção de incentivar o ensino e compreensão de aspectos modalizadores essenciais para a organização e manutenção do conteúdo semântico em língua alemã.

Filmes e quadrinhos como material didático para desenvolver o tema das PM em sala de aula de ALE podem ser aplicados através de diferentes perspectivas metodológicas, levando em conta o nível de conhecimento e interesse dos alunos. Portanto, é essencial criar um clima adequado para o ensino de PMs, e isso pode ser alcançado através de materiais autênticos, que abarquem as funções comunicativas deste elemento, tanto na linguagem escrita como falada. 
Finalmente, estudar uma LE não se restringe apenas à investigação dos aspectos lexicais e gramaticais. Integrar-se na cultura e sociedade é também uma habilidade que deve ser treinada em sala de aula. $\mathrm{O}$ conhecimento pragmático auxilia a estreitar a relação social e linguística entre brasileiros e falantes de alemão, fazendo com que o aprendiz tenha maior compreensão da língua, como ela é falada e utilizada naquela sociedade. Neste sentido, as PMs são elementos de grande importância no ensino e aprendizagem de ALE, e elas podem ser mediadas de formas sistematizadas e dinâmicas, com a aplicação de regras e atividades relevantes.

\section{Referências}

ABRAHAM, W. Introduction. In: ABRAHAM, W. (ed.). Discourse particles: descriptive and theoretical investigations on the logical, syntactic, and pragmatic properties of discourse particles in German. Amsterdam: Johns Benjamins, 1991a. p. 1-10. Doi: https://doi.org/10.1075/pbns.12

ABRAHAM, W. Discourse particles in German: how does their illocutive force come about? In: ABRAHAM, W. (ed.). Discourse particles: descriptive and theoretical investigations on the logical, syntactic, and pragmatic properties of discourse particles in German. Amsterdam: Johns Benjamins, 1991b. p. 203-252. Doi: https://doi.org/10.1075/pbns.12

ABRAHAM, W. Diskurspartikeln zwischen modalität, modus und fremdbewusstseins-abgleich (theory of mind). In: HARDEN, T. H.; HENTSCHEL, E. (ed.). 40 Jahre Partikelforschung. Tübingen: Stauffenburg, 2010. p. 33-70.

ABRAHAM, W.; LEISS, E. Modality and theory of mind elements across languages. Berlin: De Gruyter, 2012. Doi: https://doi.org/10.1515/9783110271072

AQUINO, M. A função dinâmica das partículas modais alemãs doch e ja no ensino de línguas. 2012. 110f. Dissertação (Mestrado em Estudos Linguísticos) - Faculdade de Letras, Universidade Federal de Minas Gerais, Belo Horizonte, 2012.

AQUINO, M. O esforço de processamento das partículas modais doch e wobl em tarefas de pós-edição: uma investigação processual no par linguístico alemão/português. 2016. Tese (Doutorado em Estudos Linguísticos) - Faculdade de Letras, Universidade Federal de Minas Gerais, Belo Horizonte, 2016.

AQUINO, M. O processamento das partículas modais alemãs em tarefas de pósedição. Pandaemonium Germanicum, São Paulo, v. 20, n. 30, p. 65-85, 2017a. Doi: https://doi.org/10.11606/1982-88372032156 
AQUINO, M. O questionário como ferramenta de ensino de partículas modais alemãs. Pandaemonium Germanicum, São Paulo, v. 20, n. 32, p. 156-179, 2017b. Doi: https://doi.org/10.11606/1982-88372032156

AQUINO, M.; ARANTES, P. Modalparticles and their functional equivalents in Brazilian Portuguese: analyzing modal elements in a cross-linguistic perspective. No prelo.

BUSSE, D. Partikeln im unterricht Deutsch als fremdsprache. Muttersprache, Berlin, v. 102, n. 1, p. 37-59, 1992.

CANALE, M.; SWAIN, M. Theoretical bases of communicative approaches to second language teaching and testing. Applied Linguistics, Oxford, v. 1, n. 1, p. 1-47, 1980. Doi: https://doi.org/10.1093/applin/1.1.1

CARY, S. Going graphic: comics at work in the multilingual classroom. Portsmouth: Heinemann, 2004.

CHOMSKY, N. Rules and representations. New York: Columbia University Press, 1980. Doi: https://doi.org/10.1017/S0140525X00001515

DEGAND, L.; CORNILLIE, B.; PIETRANDREA, P. Discourse markers and modal particles: two sides of the same coin? In: DEGAND, L.; CORNILLIE, B.; P. PIETRANDREA. (ed.). Discourse markers and modal particles: categorization and description. Amsterdam: John Benjamins, 2013. p. 1-18. Doi: https://doi. org/10.1075/pbns.234.01deg

DIEWALD, G. Discourse particles and modal particles as grammatical elements. In: FISCHER, K. (ed.). Approaches to discourse particles. Amsterdam: Elsevier, 2006. p. 403-426.

DIEWALD, G. Same same but different: modal particles, discourse markers and the art (and purpose) of categorization. In: DEGAND, L.; PIETRANDREA, P.; CORNILLIE, B. (ed.). Discourse markers and modal particles: categorization and description. Amsterdam: John Benjamins, 2013. p. 19-46. Doi: https://doi. org/10.1075/pbns.234.02die

DUCH-ADAMCZYK, J. Vermittlung der Abtönungspartikeln im DaF-Unterricht. In: SKOWRONEK, B. (ed.). Glottodidactica. Kraków: Wydawnictwo Naukowe UAM, 2012. p. 25-35. v. 39. Doi: https://doi.org/10.14746/gl.2012.39.1.3

DUDEN. Grammatik der deutschen Gegenwartssprache. Mannheim: Bibliographisches Institut, 2016.

HALL, K.; SCHEINER, B. Übungsgrammatik, für die oberstufe: B2/C2. München: Hueber, 2014. 
HANSEN, G. Retrospection methods in translator training and translation research. Journal of Specialised Translation, London, v. 5, p. 2-41, 2006.

HEGGELUND, K. Zur bedeutung der deutschen modalpartikeln in gesprächen unter besonderer berücksichtigung der sprechakttheorie und der daf-perspektive. Linguistik. Online, Berna, v. 9, n. 2, 2001. Doi: https://doi.org/10.13092/lo.9.969

HELBIG, G. Lexikon dentscherpartikeln. 2. ed. Leipzig: Verlag Enzyklopädie, 1990. HELBIG, G.; KÖTZ, W. Die partikeln. Leipzig: Verlag Enzyklopädie, 1991.

HENTSCHEL, E. Wenn partikeln frech werden. In: HELD, G. (Ed.). Partikeln und böflichkeit. Berlin: Peter Lang, 2003. p. 55-72.

HENTSCHEL, E.; WEYDT, H. Der pragmatische mechanismus: denn und eigentlich. In: WEYDT, H. (ed.). Partikeln und interaktion. Tübingen: Niemeyer, 1983. p. 263-273. Doi: https://doi.org/10.1515/9783111661643.263

HENTSCHEL, E.; WEYDT, H. Handbuch der deutschen grammatik. Berlin: De Gruyter, 2013. v. 4. Doi: https://doi.org/10.1515/9783110312973

JOHNEN, T. Aí como partícula modal do português. In: MOTA, J. (ed.). CONGRESSO INTERNACIONAL DA ASSOCLAÇÃO BRASILEIRA DE LINGUÍSTICA, 1., 1994, Salvador. Anais [...]. Salvador: Instituto de Letras da Universidade Federal da Bahia, 1997. p. 3-9. Disponível em: https://bit. ly/2WX8Jog. Acesso em: 24 jun. 2019.

KIENPOINTNER, M. Unhöfliche partikeln? Kompetitive verwendung von partikeln in der Alltagskonversation. In: HELD, G. (ed.). Partikeln und höflichkeit. Berlin: Peter Lang, 2003. p. 73-94.

KRIVONOSOV, A. Zum problem der klassifizierung der deutschen partikeln. In: WEYDT, H. (ed.). Sprechen mitpartikeln. Berlin: De Gruyter, 1989. p. 30-38.

LEISS, E. Epistemicity, evidentiality, and Theory of Mind (ToM). In: ABRAHAM, W. Modality and theory of mind: elements across languagues. Berlin: De Gruyter, 2012. p. 37-66.

LOCHTMANN, K.; DE BOE, S. Die soziolinguistische kompetenz bei daf-lernenden und die rolle der modalpartikeln. Zeitschrift für Interkulturellen Fremdsprachenunterricht, [S.l.], v. 18, n. 2, p. 142-156, 2013.

MEIRELES, S. Onomatopeias e interjeições em histórias em quadrinhos em língua alemã. Pandaemonium Germanicum, São Paulo, v. 11, p. 157-188, 2007. Doi: https:// doi.org/10.11606/1982-8837.pg.2007.62158

MÖLLERING, M. Teaching German modal particles: a corpus-based approach. Language Learning \& Technology, Santa Barbara, v. 5, p. 130-151, 2001. 
NAPOLITANO, M. Como usar o cinema na sala de aula. São Paulo: Contexto, 2003. RÖSLER, D. Teaching German modal particles. International Review of Applied Linguistics, [S. l.], v. 20, n. 1, p. 33-38, 1982. Doi: https://doi.org/10.1515/ iral.1982.20.1-4.33

SOUZA, M. Funções comunicativas de partículas modais alemãs em fóruns de discussão na internet. 2008. Dissertação (Mestrado em Língua Alemã) Departamento de Letras modernas, Universidade de São Paulo, São Paulo, 2008. SPERBER, D.; WILSON, D. Teoria da relevância. Linguagem em Discurso, Tubarão, v. 5, número especial, p. 221-268, 2005.

THURMAIR, M. Alternative überlegungen zur didaktik von modalpartikeln. Deutsch als Fremdsprache, Regensburg, v. 47, n. 1, p. 3-9, 2010.

WALTEREIT, R.; DETGES, U. Different functions, different histories: modal particles and discourse markers from a diachronic point of view. Catalan Journal of Linguistic, Barcelona, v. 6, p. 61-80, 2007. Doi: https://doi.org/10.5565/rev/ catjl.124

WELKER, H. Asparticulas modais no alemão e no português e as equivalências de aber, eben, etwa e vielleicht. 1990. Dissertação (Mestrado em Língua Alemã) - Departamento de Linguística, Universidade de Brasília, Brasília, DF, 1990.

WENZEL, V. Relationelle strategien in der fremdsprache: pragmatische und interkulturelle aspekte der niederländischen lernersprache von deutschen. Münster: Agenda Verlag, 2002.

WEYDT, H. Abtönungspartikel: die deutschen modalwörter und ihre französischen entsprechungen. Berlin: Gehlen, 1969.

WEYDT, H. Kleine deutsche Partikellehre: ein Lehr- und Übungsbuch für Deutsch als Fremdsprache. Stuttgart, 1983.

WEYDT, H. (Warum) Spricht man mit partikeln überhaupt höflich? In: HELD, G. (ed.). Partikeln und höflichkeit. Frankfurt: Peter Lang, 2003. p. 13-39.

WEYDT, H. What are particles good for? In: FISCHER, K. (ed.). Approaches to discourse particles. Amsterdam: Elsevier, 2006. p. 205-218. (Studies in Pragmatics, 1) WIERZBICKA, A. Cross-cultural pragmatics. Berlin: De Gruyter, 1991.

ZIMMERMAN, K. Warum sind modalpartikeln ein lernproblem? In: WEYDT, H. (ed.). Partikeln und deutschunterricht. abtönungspartikeln für lerner des deutschen. Heidelberg: Julius Groos, 1981. p. 111-122.

Data de submissão: 11/12/2018. Data de aprovação: 13/06/2019. 